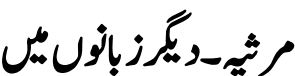

\section{Elegy in other Languages}

Tahir Hussain Khoso*

Dr. Muhammad Yar Gondal ${ }^{* *}$

\section{Abstract}

Elegy started its journey from Arabic Language. Its first creator was Hazrat Adam (AS) at sorrowful murder of his sons Habeel. This article is about the origin and meaning of the word "Elegy", Elegy in Urdu language its evolution and beginning. In Urdu language, Elegy started from Dakkan.Elegy had been divided into three types which were conventional, personal and religious or KarbalaiMarsiya.But later on, it became specific for Karba. We can come across personal elegies in Urdu but whenever we mention elegy our attention goes to Karbala. Therefore, in this article Elegy has been discussed in this context. Elegy in different languagesof the world like Greek, Latin, English, French, Italian etc. is also part of this article.

Keywords: Sorrowful, Murder, Elegy, Evolution, Conventional, Religious

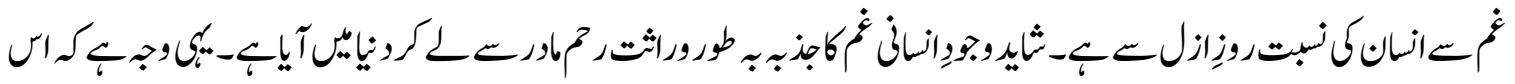

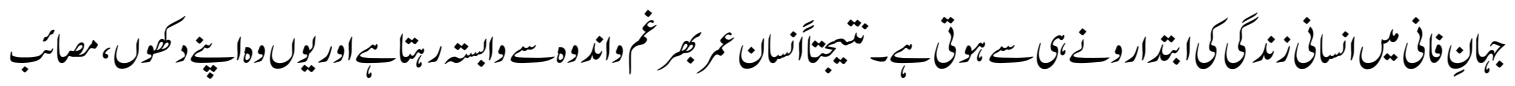

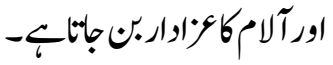

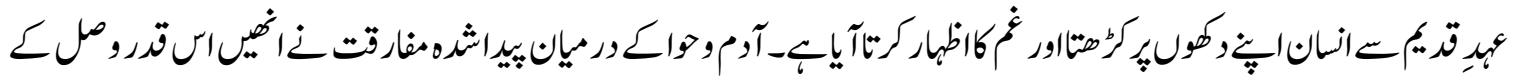

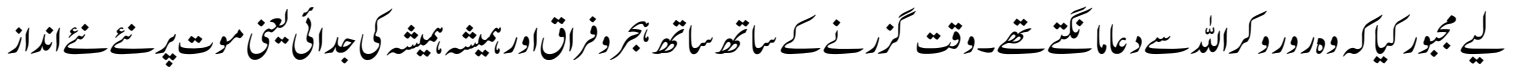

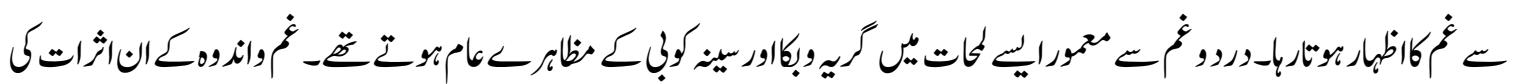

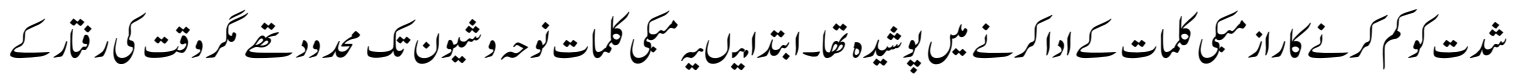

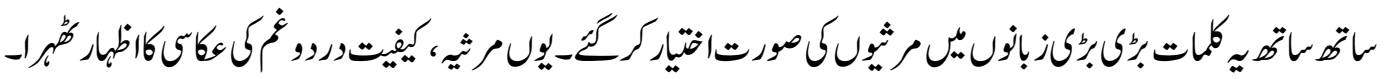

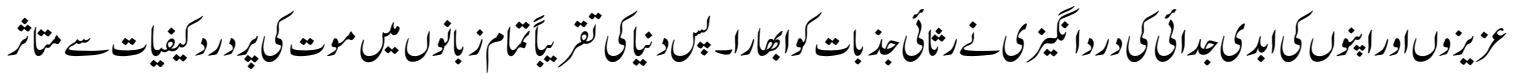

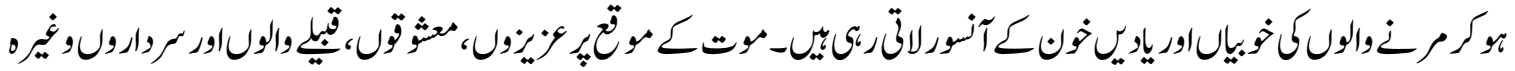

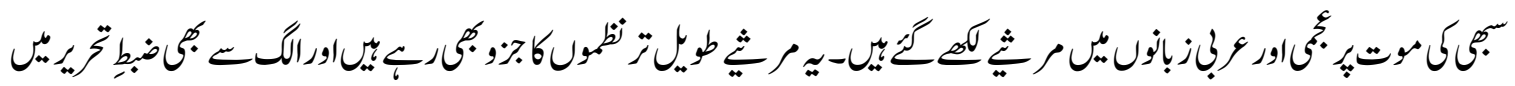

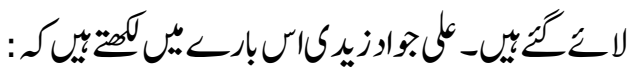

${ }^{*}$ Research Scholar, Ph.D Urdu, UOS, Sargodha.

Email: marshman156@gmail.com_ ORCID iD:https://orcid.org/0000-0002-9284-5590

${ }^{* *}$ Assistant Professor, Department of Urdu \& Oriental Languages, UOS, Sargodha. 


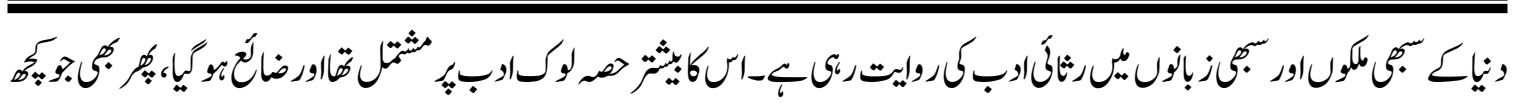

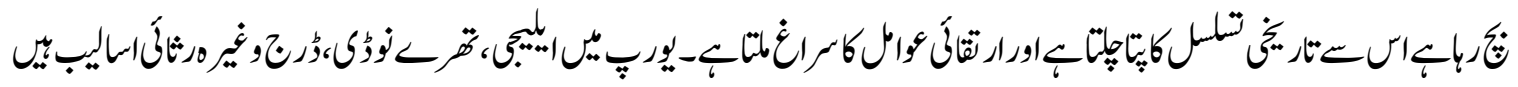

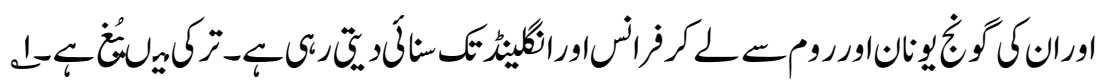

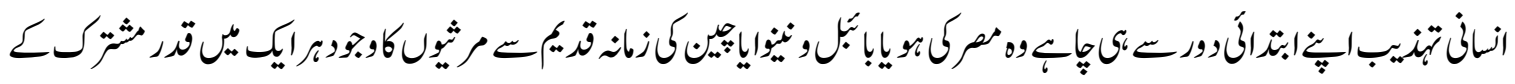

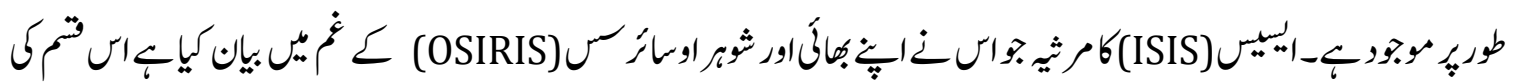

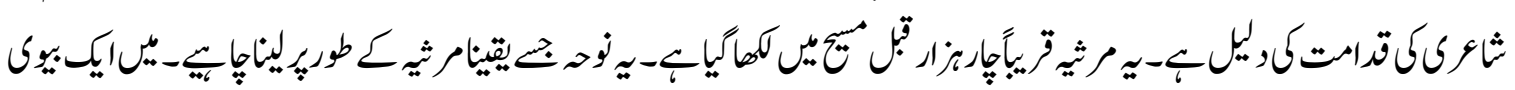

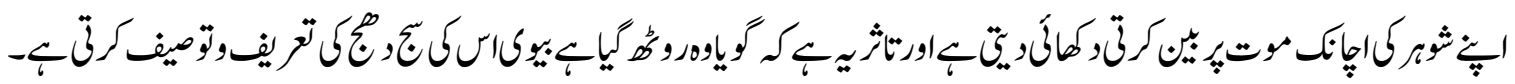

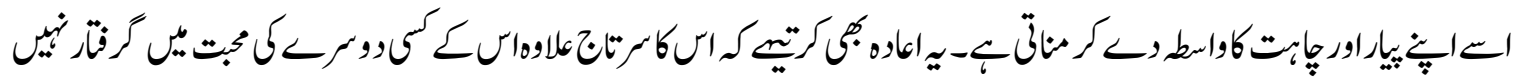

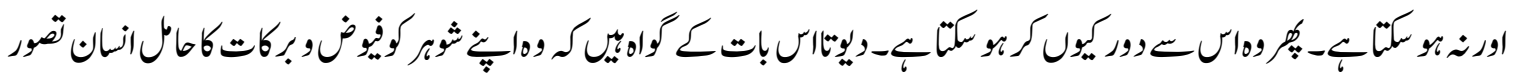

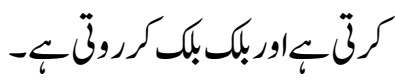

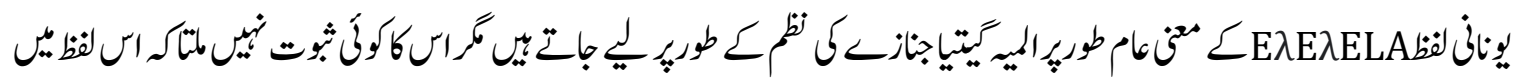

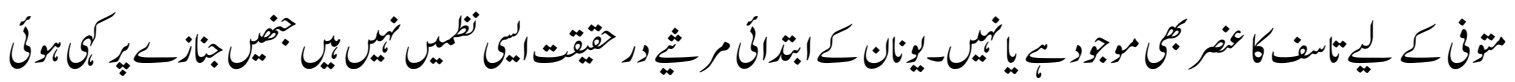

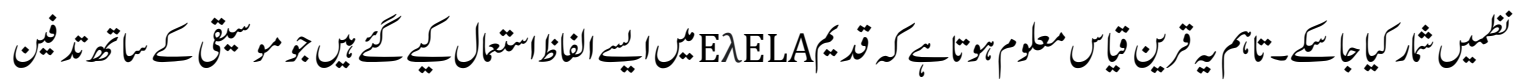

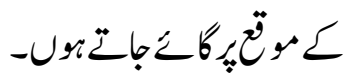

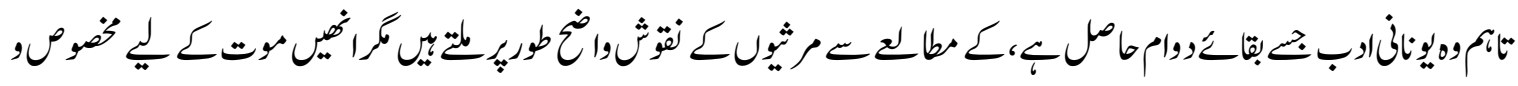

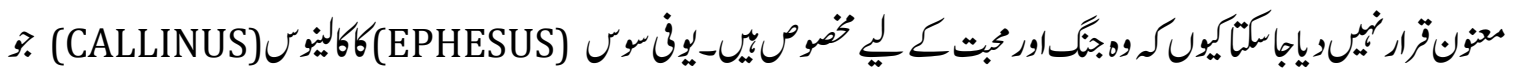

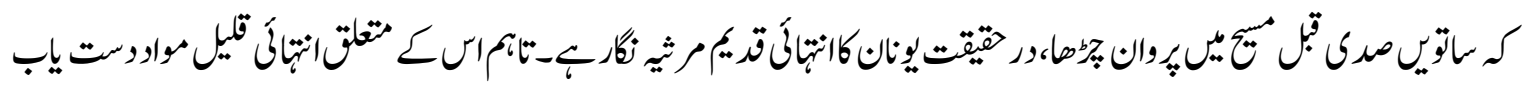

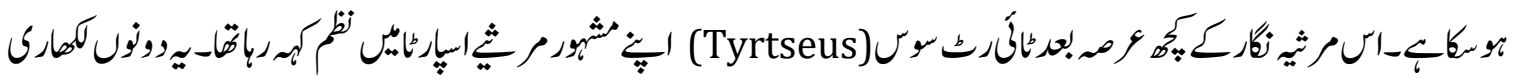

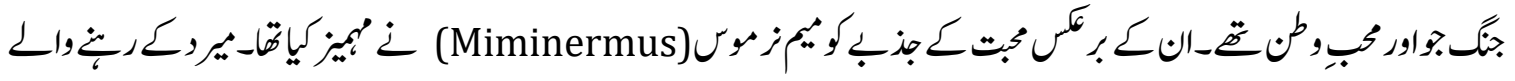

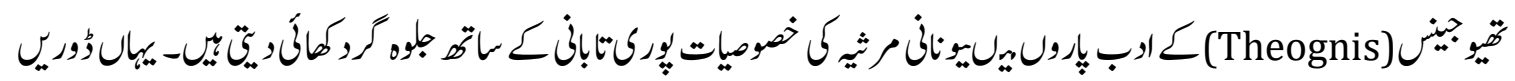
(Dorian)

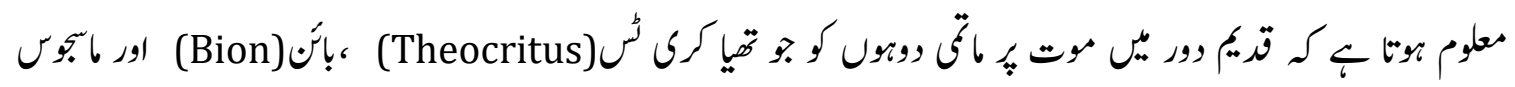

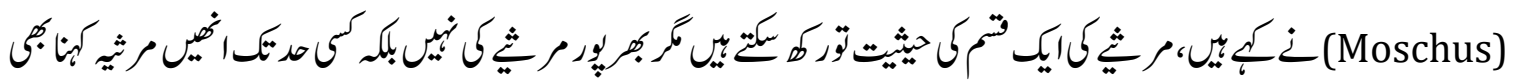

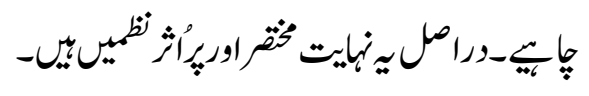




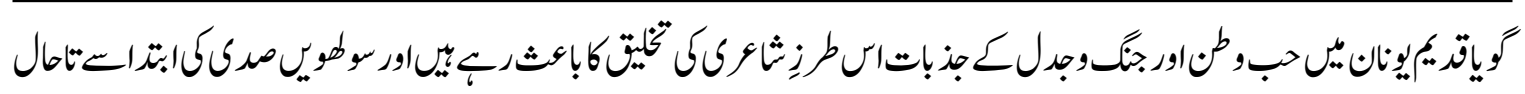

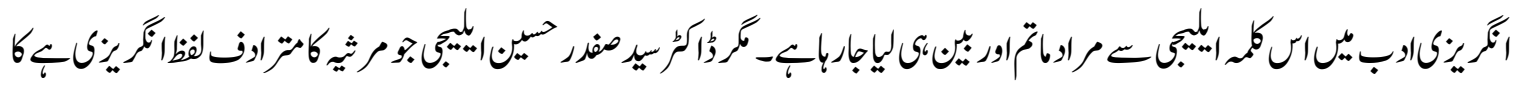

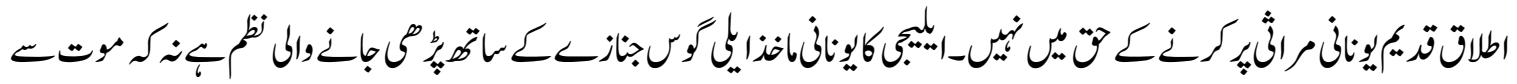

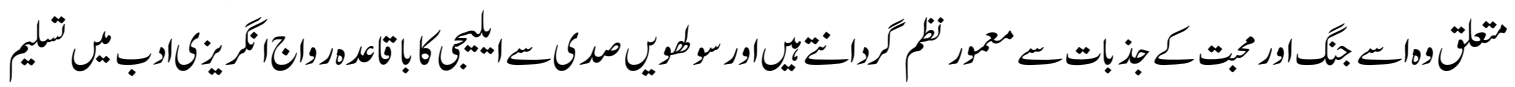

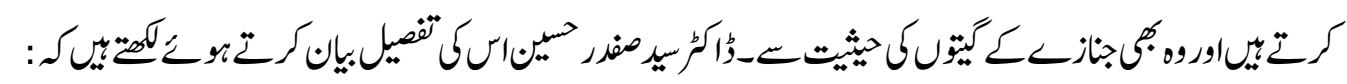

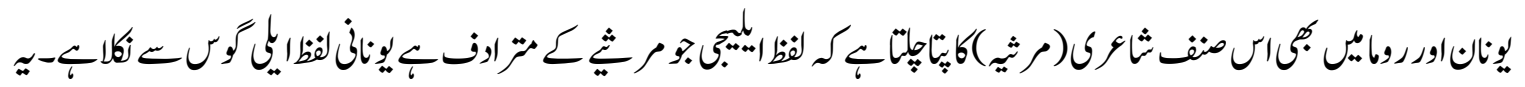

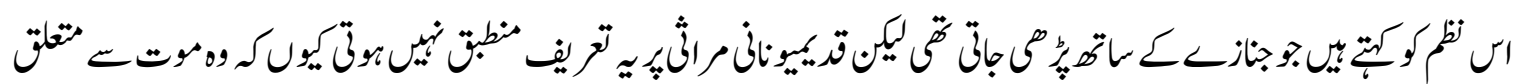

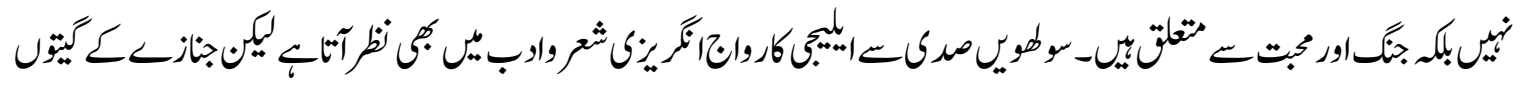

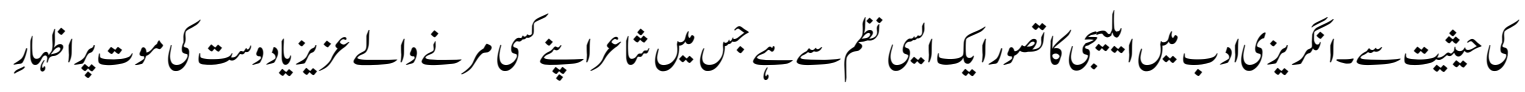

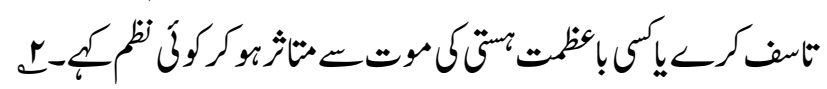

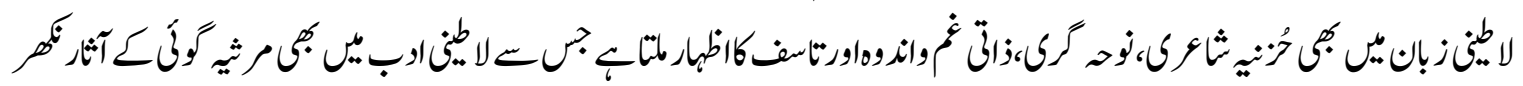

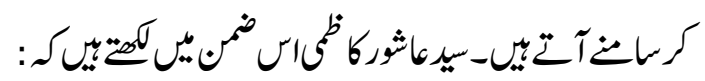

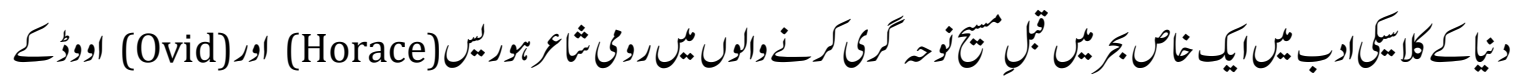

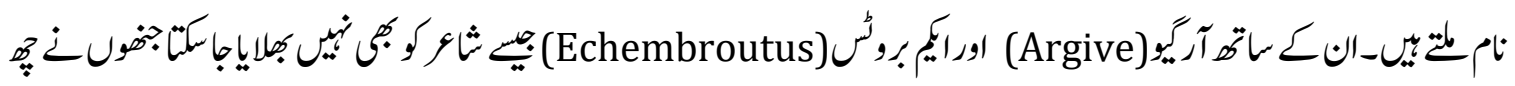

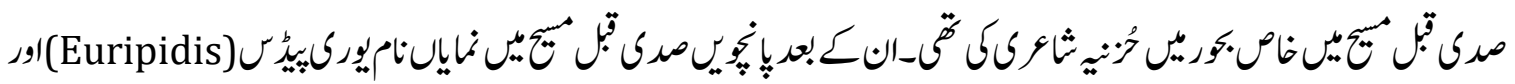

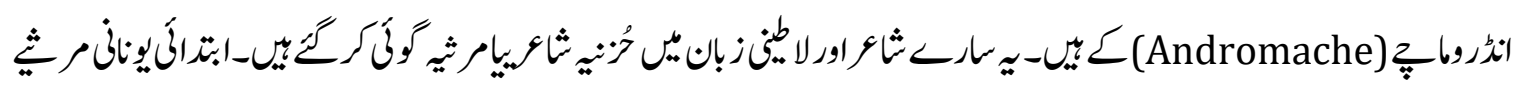

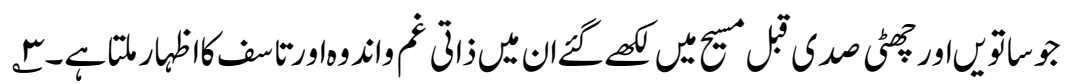

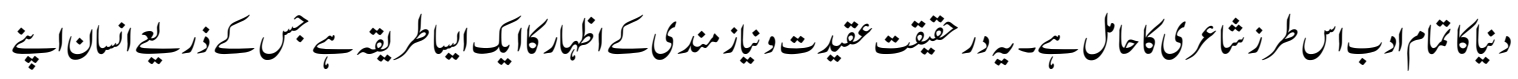

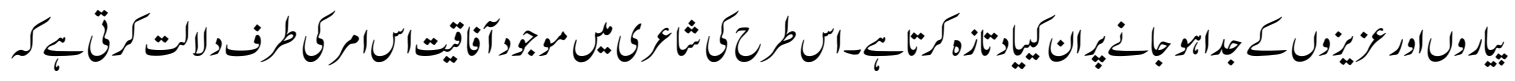

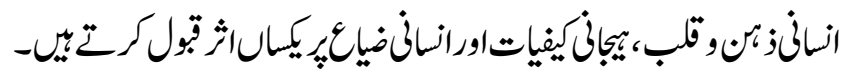

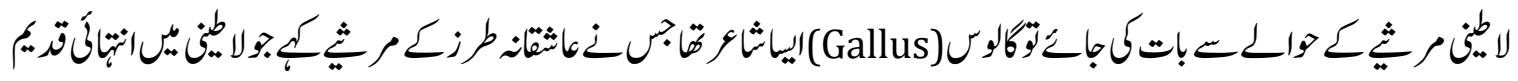

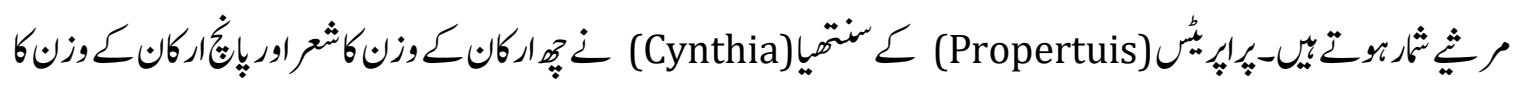

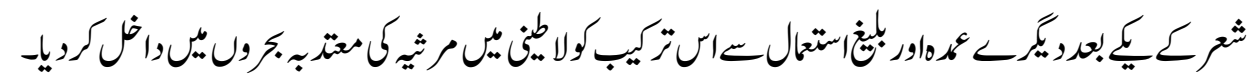

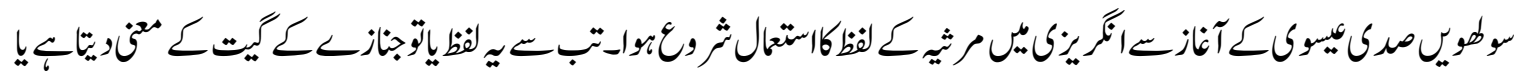




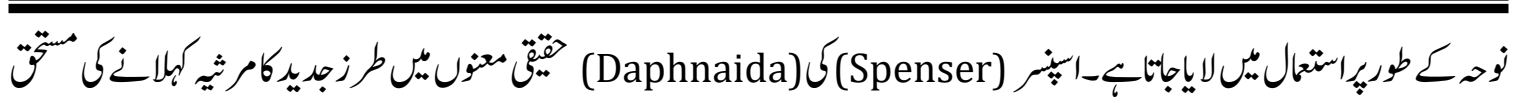

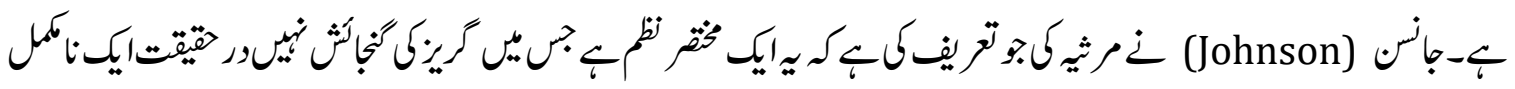

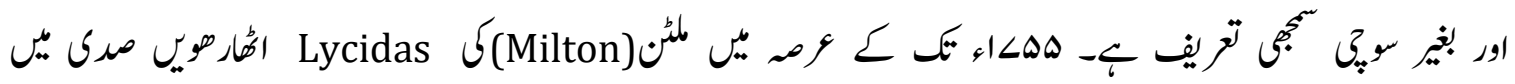

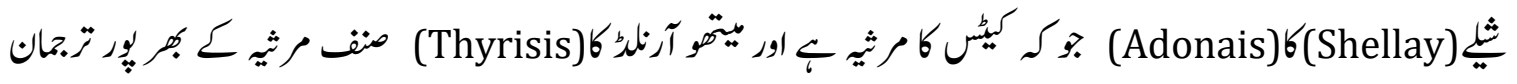

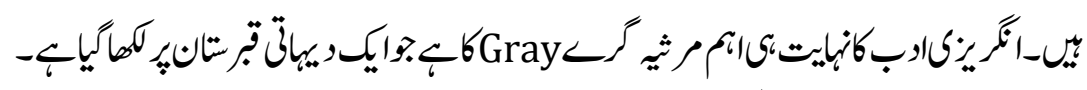

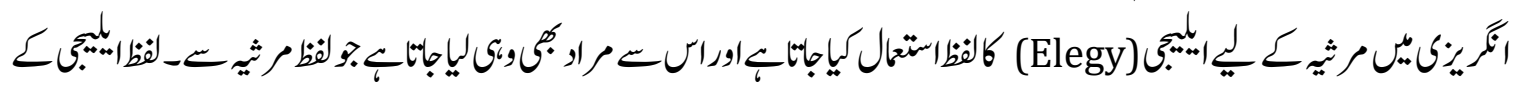

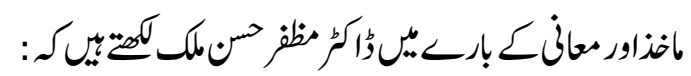

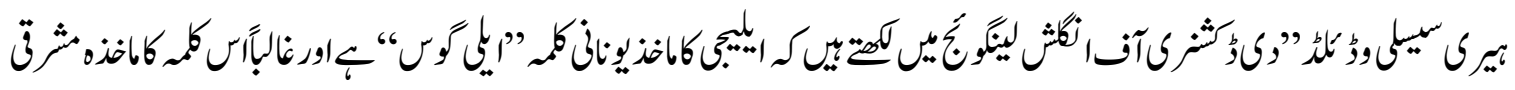

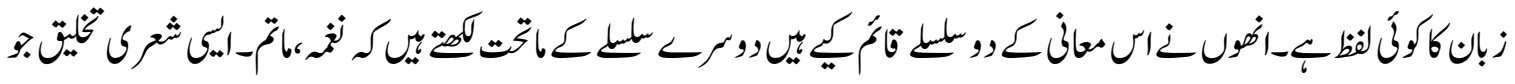

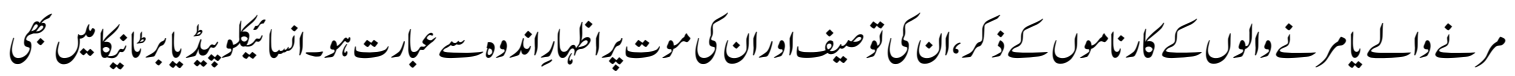

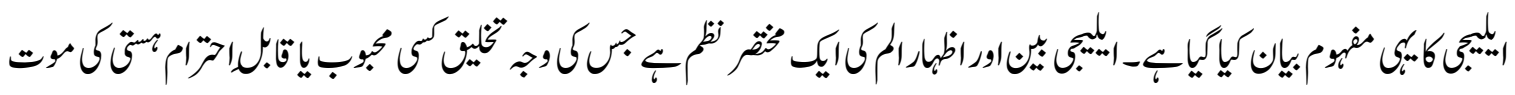
r

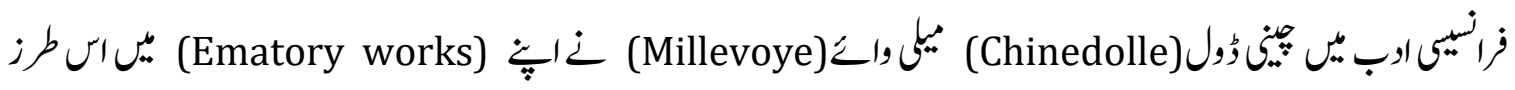

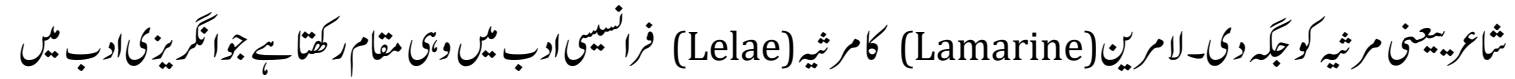

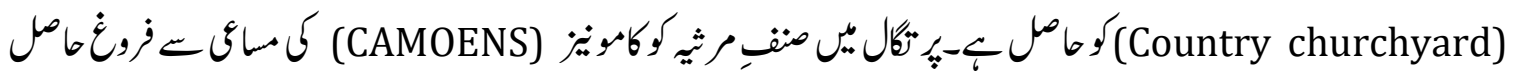

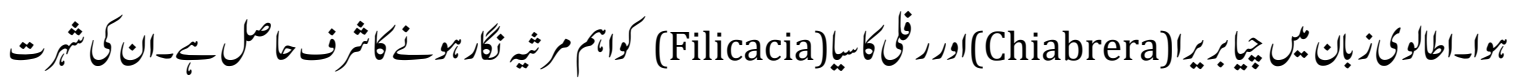

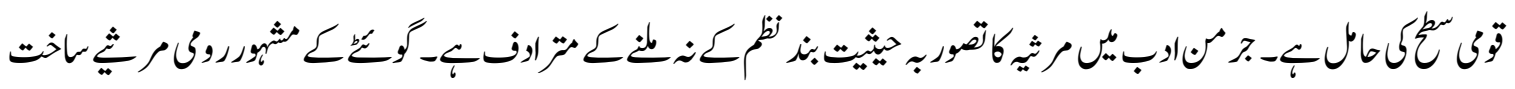

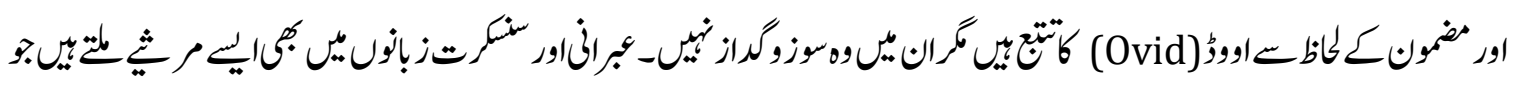

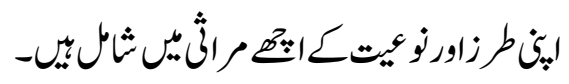

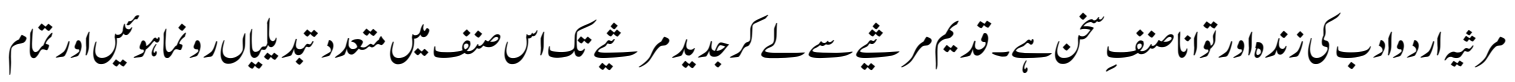

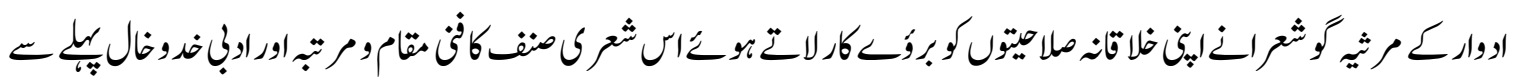

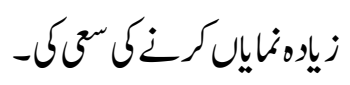

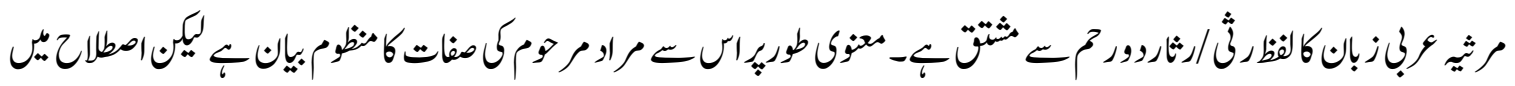

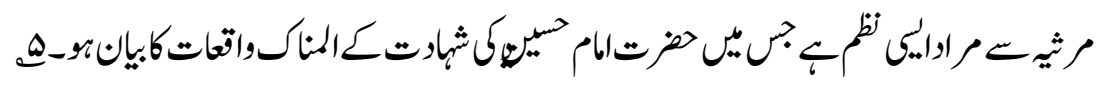




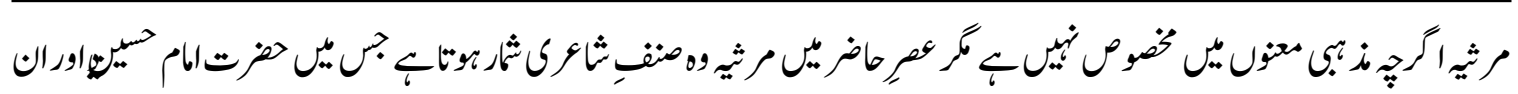

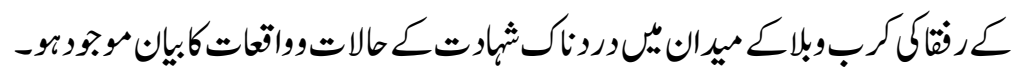

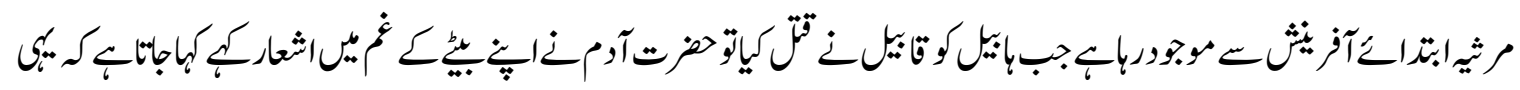

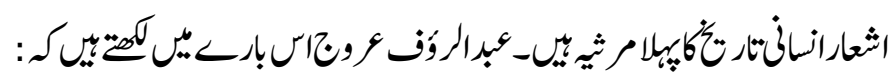

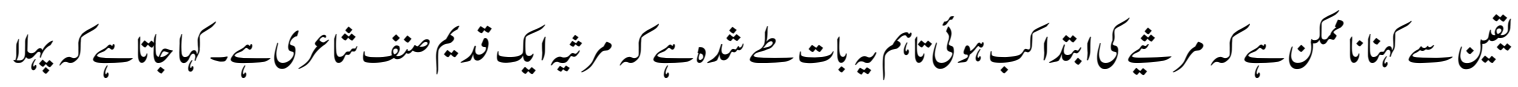

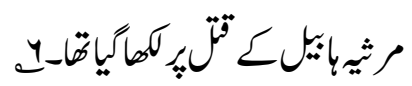

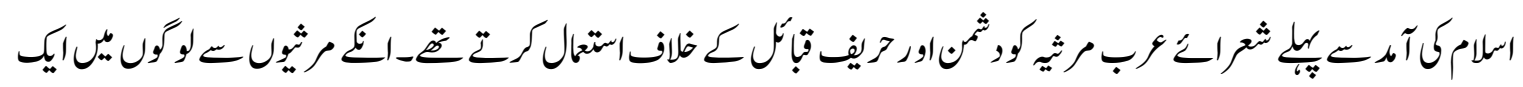

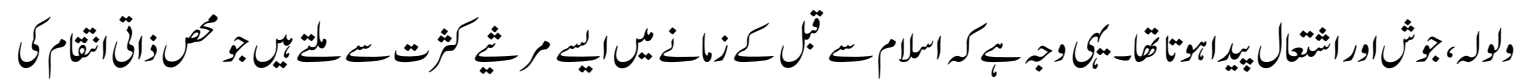

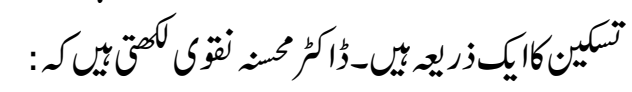

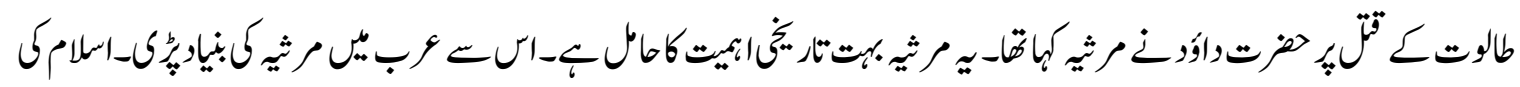

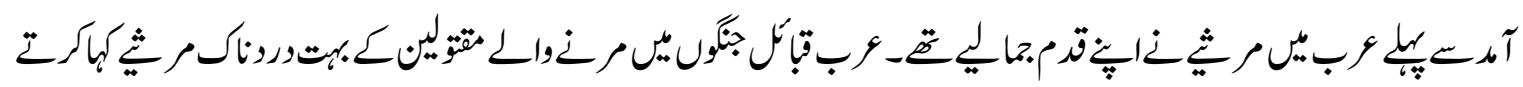

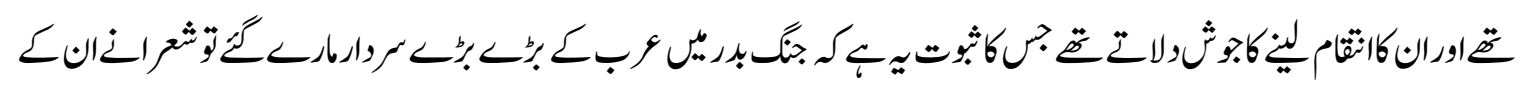

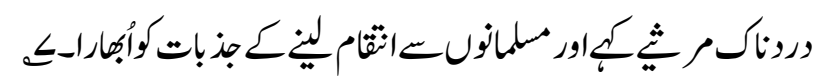

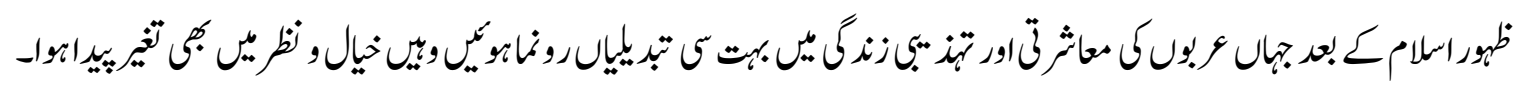

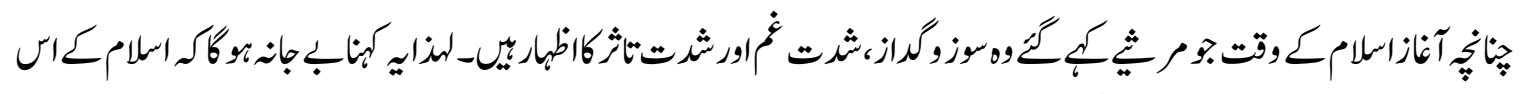

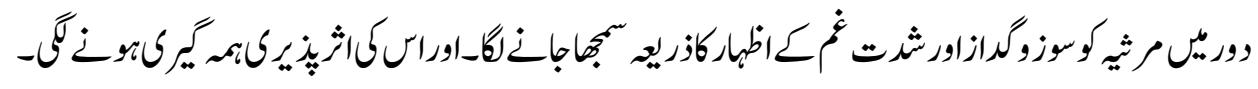

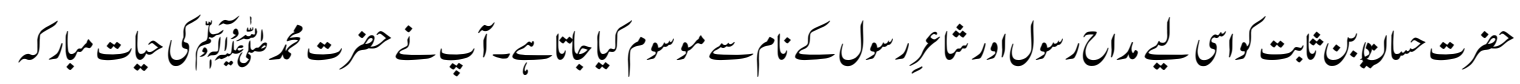

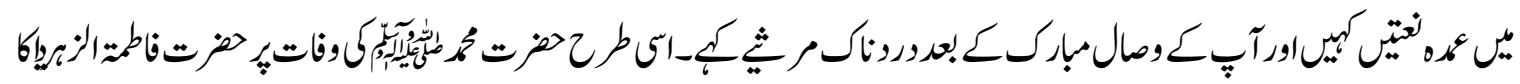

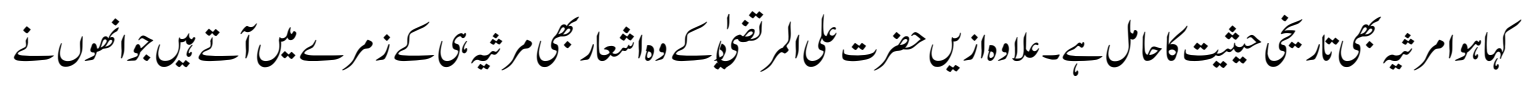

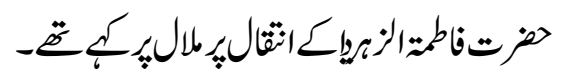

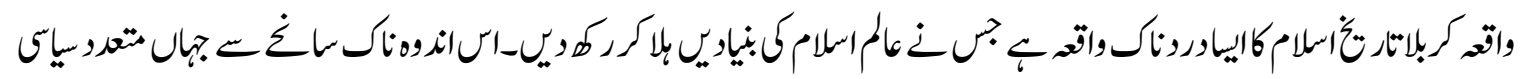

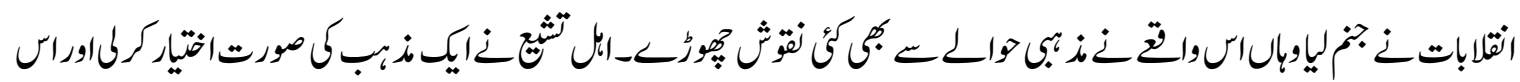

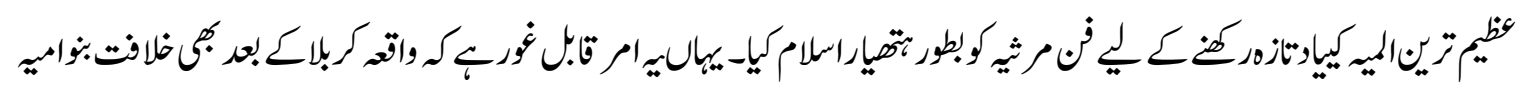

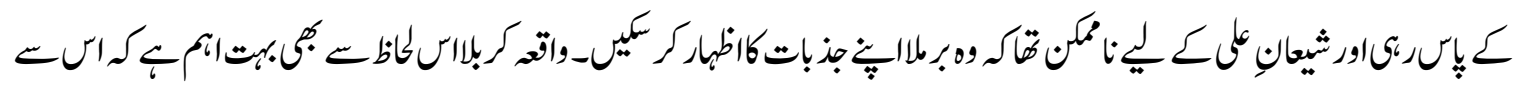




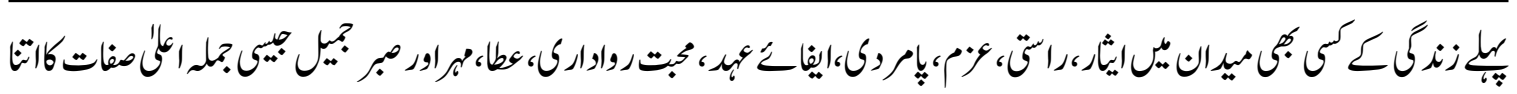

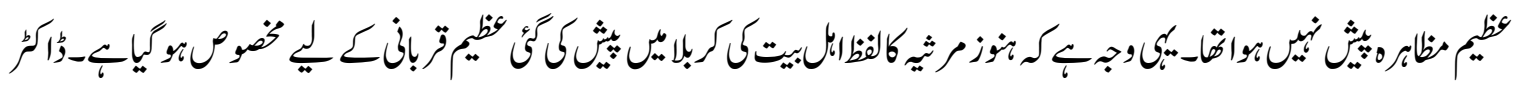

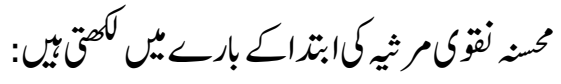

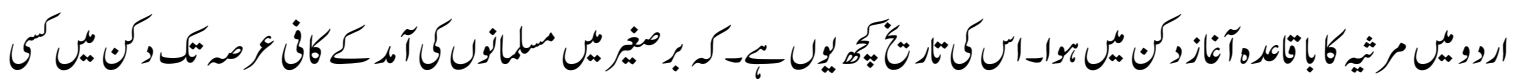

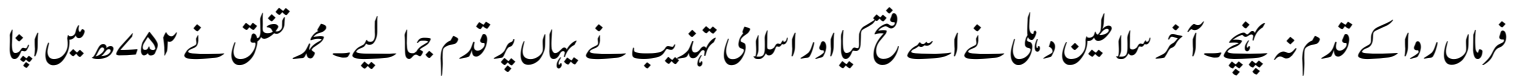

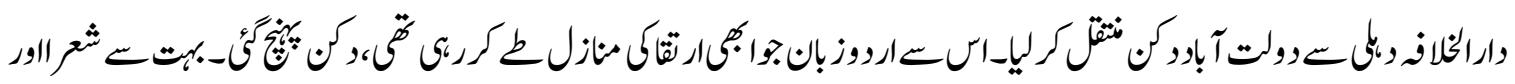

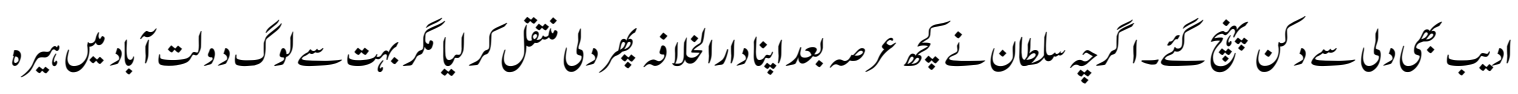

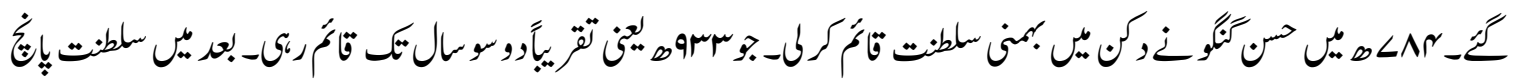

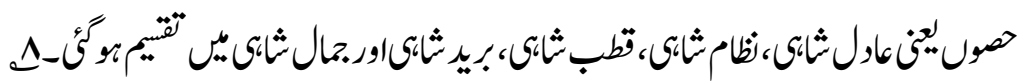

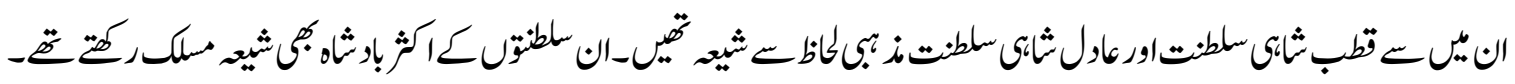

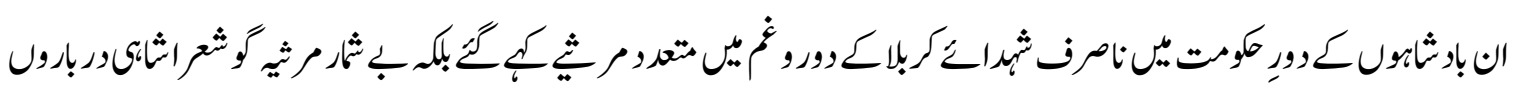

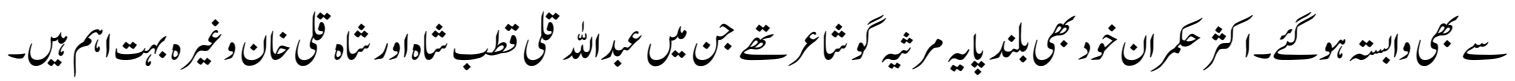

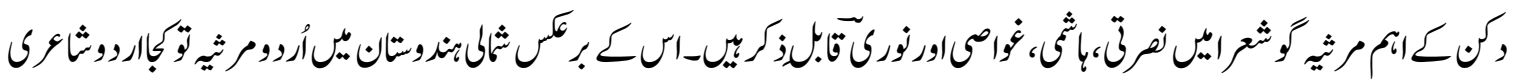

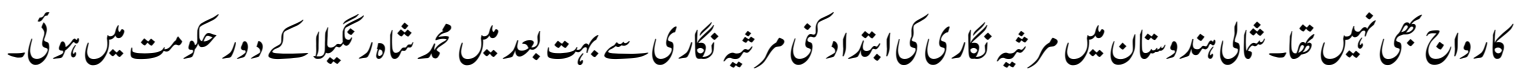

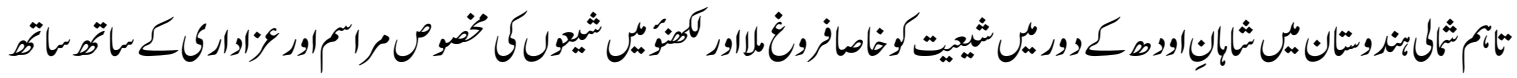

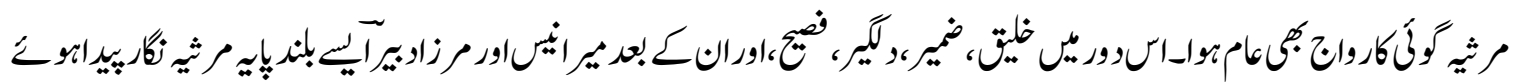

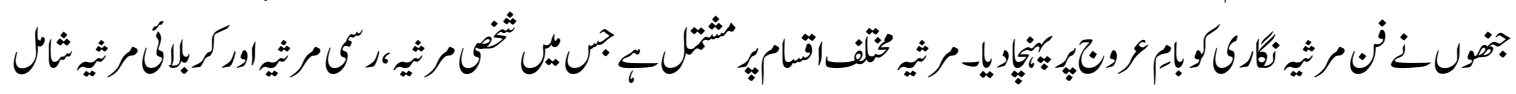

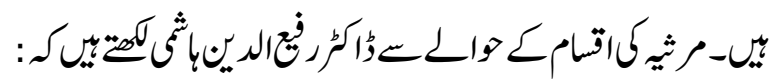

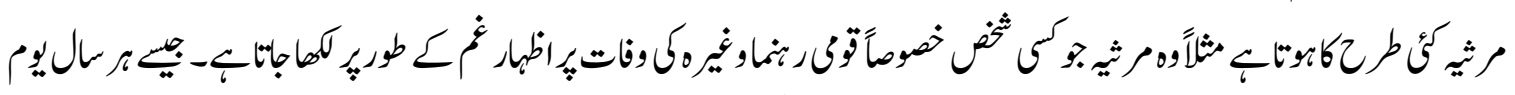

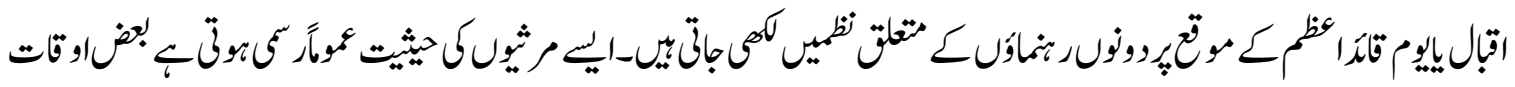

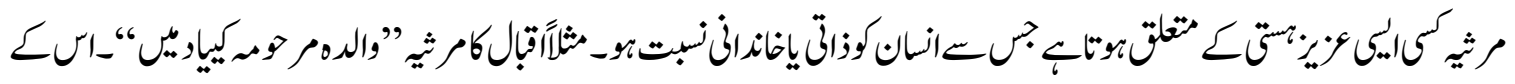

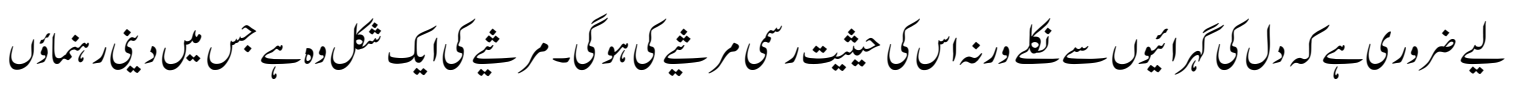

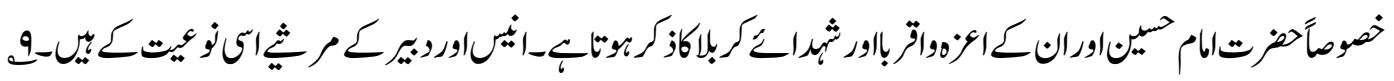

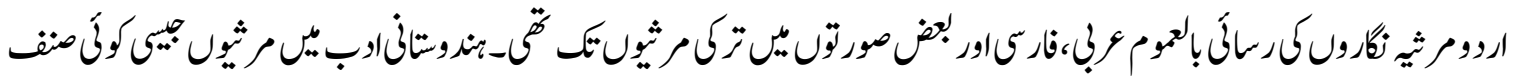




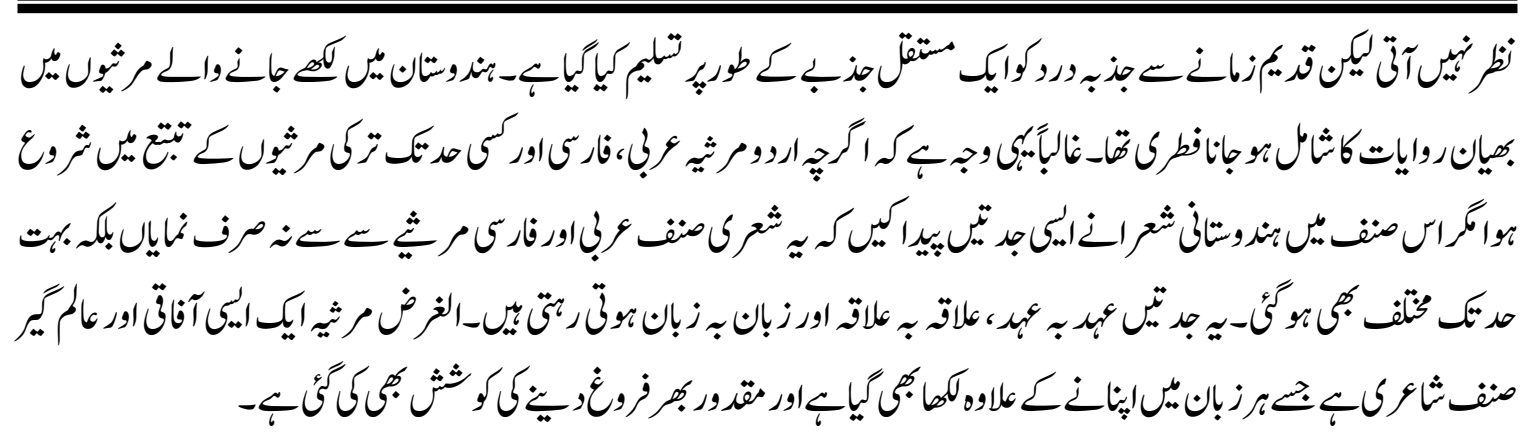

\section{References}

1. Ali Jawad Zaidi, Dehlvi Marsia Goo(Karachi: Nafees Academy, 1988),P9-10.

2. Syed Safdar Hussain, Tareekh Marsia Goie Maa Baad Anees Lahore: Colletion Dial Singh Trust Library, N.D), P4-5.

3. Syed Ashoor Kazmi, Urdu Marsiay ka Safar(Dehli: Educational Publishing House, 2006),P43-44

4. Dr. Muzaffar Hasan Malik, Urdu Marsiay mein Mirza Dabeer ka Maqam(Lahore: Maqbool Academy, 1976),P175-176

5. Dr. Saleem Akhtar, Tanqeedi Istalahat Touzihi Lughut (Lahore: Sang-e-Meel Publications, 2011),P240

6. Abdur Rauf Orooj, Urdu Marsia key Panch Sau Saal(Karachi: Sarak Publications, NA),P3

7. Dr. Mohsina Naqvi, Marsia aur us ki Tadrees, Paigham Aashna, Article,63(2015),P15

8. Dr. Mohsina Naqvi, Marsia aur us ki Tadrees, P12

9. Dr.Rafi ud Din Hashmi, Asnaf-e-Adab (Lahore: Sang-e-Maeel Publications, 2008),P51 